\title{
Cost-effectiveness of intravenous proton pump inhibitors in high-risk bleeders
}

\author{
Sander Veldhuyzen van Zanten MD FRCPC
}

Enns RA, Gagnon YM, Rioux KP, Levy AR. Costeffectiveness in Canada of intravenous proton pump inhibitors for all patients presenting with acute upper gastrointestinal bleeding. Aliment Pharmacol Ther 2003; 17:225-33.

$\mathrm{T}$ here is unequivocal evidence that proton pump inhibitors (PPIs) are currently the most effective acid suppressive agents available. Intravenous (IV) formulations have been developed, although only IV pantoprazole is available in Canada. In patients presenting with serious upper gastrointestinal (GI) bleeding due to duodenal or gastric ulcers, it has always been believed that IV administration of acid-lowering agents would improve clinical outcomes. The reason behind this thinking is twofold. First, there is in vitro evidence that formed clots are more stable at or near neutral pH (1). Second, by administering the agent intravenously, suppression of acid production is achieved much more quickly, thereby promoting more rapid healing of the ulcer and reducing the risk of persistent or recurrent bleeding. Interestingly and surprisingly, however, the data for intravenous $\mathrm{H}_{2}$-blockers have been disappointing (2). This failure to demonstrate clinical benefit has never been fully explained.

Over the past few years, several studies have been published that suggest that IV PPIs may reduce the incidence of rebleeding and the requirement for either blood transfusions or surgical intervention. Furthermore, a decrease in the length of hospital stay can also be expected and would result in cost savings.

Using the data from a pivotal Hong Kong study that showed the benefit of IV PPI use (3), and incorporating Canadian health care cost data and the best estimates from the literature about important outcomes (length of hospital stay and rates of rebleeding, surgery and death), Enns and colleagues performed a very comprehensive cost-effectiveness analysis of the use of IV pantoprazole. In their model, the first approach was to administer IV PPIs to all patients presenting to the emergency room with evidence of serious upper GI bleeding, including melena or hematemesis. The second approach was to withhold IV PPIs from all patients and provide standard treatment, with endoscopic therapy if there were high-risk stigmata for bleeding, such as signs of active bleeding, a visible vessel or overlying clot.

The analysis had a 60-day horizon and was based on payments from a third-party perspective, such as Provincial Ministries of Health. The following outcomes were used in the IV PPI group: endoscopic treatment was given if a high-risk ulcer was identified, the IV PPI was continued, patients were then monitored and failures were treated with either repeat endoscopy or surgery. In the control group, no IV PPIs were given, but therapeutic endoscopy was performed if high-risk stigmata were seen. Patients were again followed and failures were treated either surgically or by repeat endoscopies. It was assumed that such patients would receive a 30-day treatment with a standard oral PPI regimen. Similarly, in the IV PPI group, patients who did not have high-risk stigmata received a 30-day course of oral PPIs. Using published data on the success rates of therapeutic endoscopy, IV PPIs, repeat endoscopy and surgery, it was convincingly shown that the use of IV PPI was cost-effective. Using a hypothetical cohort of 1000 patients, the use of IV PPI resulted in a mean savings of $\$ 20,700$ and the prevention of 37 episodes of rebleeding. It is important to stress that it was assumed in the model that all patients would undergo endoscopy on average $24 \mathrm{~h}$ after presentation. This timeframe certainly makes clinical sense and is in keeping with the Canadian Registry on Nonvariceal Upper Gastrointestinal Bleeding and Endoscopy (RUGBE), which showed that $76 \%$ of patients underwent endoscopy within $24 \mathrm{~h}$ (4). The use of IV PPIs remained cost-effective when several of the outcomes were varied in a sensitivity analysis.

This carefully conducted study supports the use of IV PPIs in patients who present to the emergency department with significant upper GI bleeding. A recent Canadian cost-effectiveness analysis by Barkun et al (5) confirmed that high-dose IV PPIs are more cost-effective than either high-dose oral PPIs or placebo. The cumulative evidence therefore certainly supports the use of IV PPIs in patients presenting with significant upper GI bleeding.

In practice, a few other issues need to be considered. First of all, from a hospital prospective, IV PPIs may be overutilized. In

Division of Gastroenterology, Dalhousie Medical School, Queen Elizabeth II Health Sciences Centre, Halifax, Nova Scotia

Correspondence: Dr Sander Veldhuyzen van Zanten, Division of Gastroenterology, Dalhousie Medical School, Queen Elizabeth II Health Sciences Centre, 1278 Tower Road, Room 928 Victoria Building, Halifax, Nova Scotia B3H 2Y9. Telephone 902-473-1499,

fax 902-473-6891, e-mail zanten@dal.ca 
the study by Enns et al, it was assumed that patients presented with "serious GI bleeding", but this is a loosely used term in the emergency room setting. Clearly, a patient who is vomiting bright red blood or is having active melena is different from a patient who presents with coffee ground emesis and normal hemoglobin. Physicians performing endoscopies are very aware of this issue. In reality, the decision to start PPIs, however, is often not taken by the endoscopist but by the referring physician. The other important situation in which savings are possible is the discontinuation of IV PPIs in patients who are

\section{REFERENCES}

1. Green FW Jr, Kaplan MM, Curtis LE, Levine PH. Effect of acid and pepsin on blood coagulation and platelet aggregation. A possible contributor prolonged gastroduodenal mucosal hemorrhage. Gastroenterology 1978;74:38-43.

2. Walt RP, Cottrell J, Mann SG, Freemantle NP, Langman MJ. Continuous intravenous famotidine for haemorrhage from peptic ulcer. Lancet 1992;340:1058-62.

3. Lau JY, Sung JJ, Lee KK, et al. Effect of intravenous omeprazole on recurrent bleeding after endoscopic treatment of bleeding peptic ulcers. N Engl J Med 2000;343:310-6. proven not to require them, including those without high-risk lesions at endoscopy. Such patients could readily be switched to oral PPIs, if necessary, at twice the standard dosage.

In summary, IV PPIs now are the accepted standard of care in patients presenting with serious upper GI bleeding. They should be continued for up to $72 \mathrm{~h}$ in patients who have highrisk endoscopic findings. Importantly, many patients who turn out to have less severe endoscopic lesions can and should be switched to oral PPIs, thereby avoiding the unnecessary use of the more expensive IV formulation.

4. Barkun A, Sabbah S, Enns R, et al, and the RUGBE Investigators. The Canadian Registry on Nonvariceal Upper Gastrointestinal Bleeding and Endoscopy (RUGBE): Endoscopic hemostasis and proton pump inhibition are associated with improved outcomes in a real-life setting. Am J Gastroenterol 2004;99:1238-46.

5. Barkun AN, Herba K, Adam V, Kennedy W, Fallone CA, Bardou M. The cost-effectiveness of high-dose oral proton pump inhibition after endoscopy in the acute treatment of peptic ulcer bleeding. Aliment Pharmacol Ther 2004;20:195-202. 


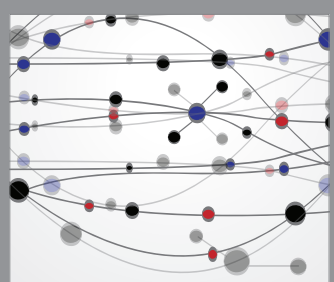

The Scientific World Journal
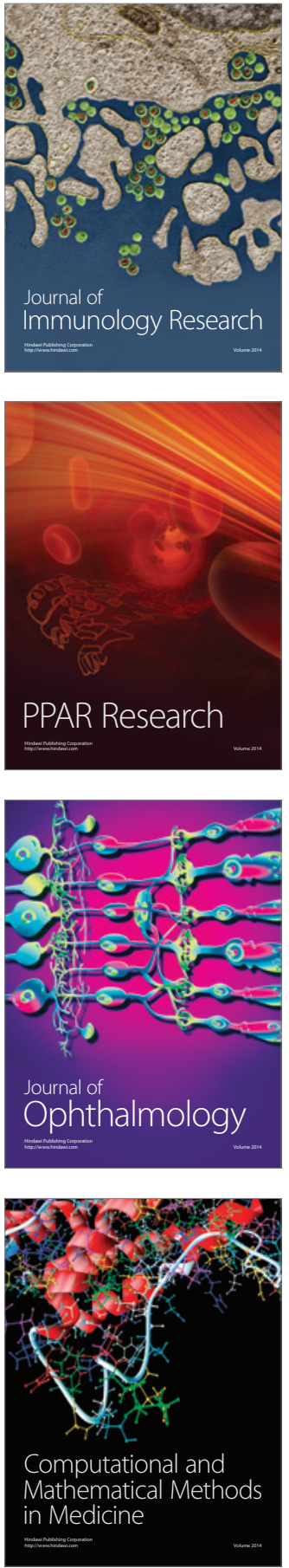

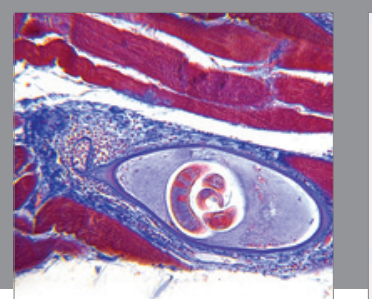

Gastroenterology Research and Practice

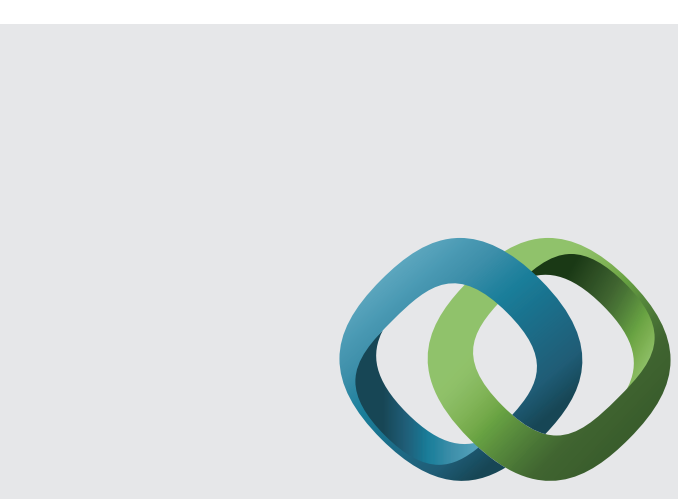

\section{Hindawi}

Submit your manuscripts at

http://www.hindawi.com
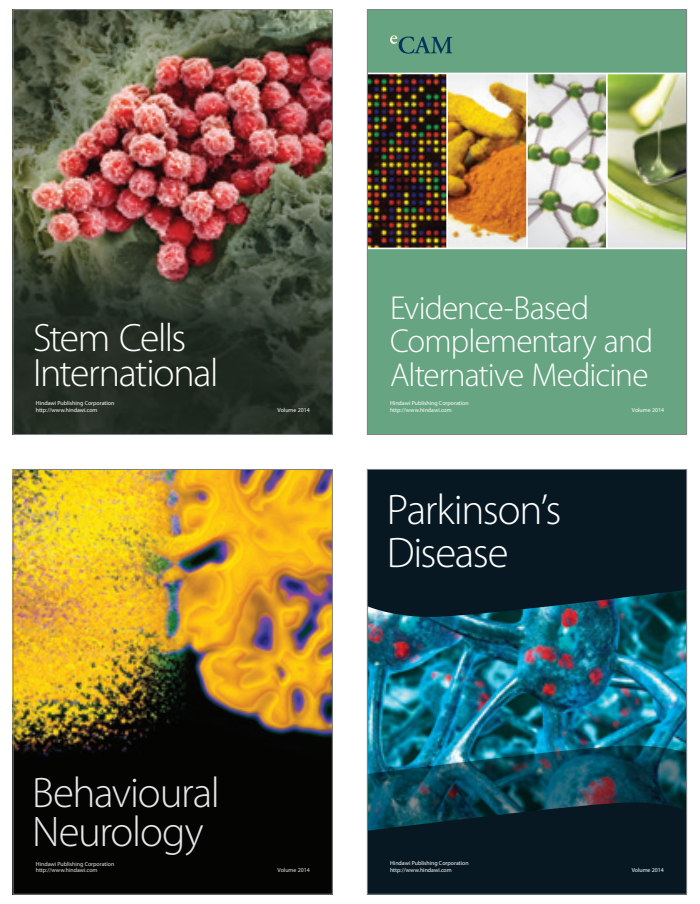
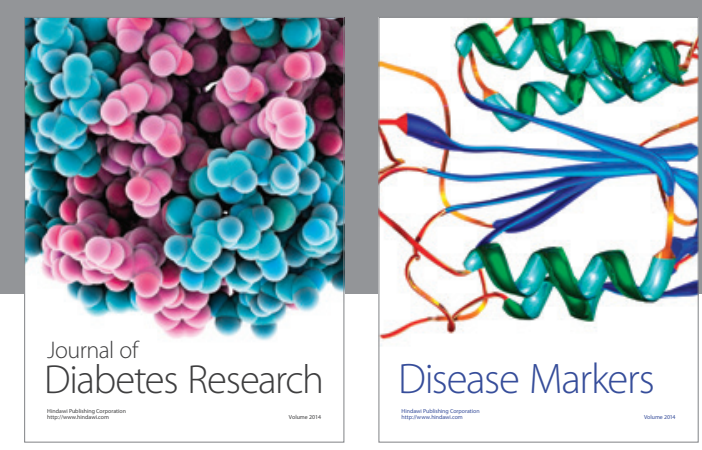

Disease Markers
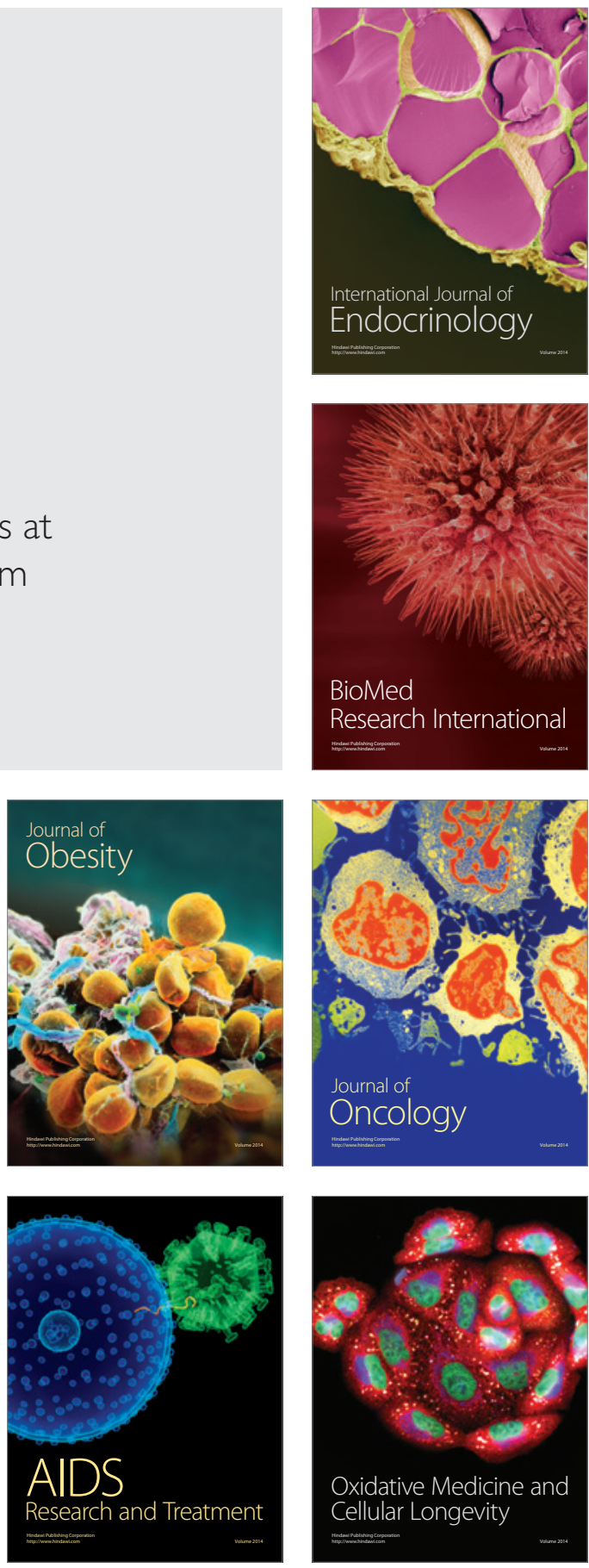